Doi: http://dx.doi.org/10.5212/OIharProfr.v.12i2.233256

\title{
OS PARÂMETROS CURRICULARES NACIONAIS NO CONTEXTO DA REFORMA EDUCACIONAL BRASILEIRA $^{1}$
}

\author{
NATIONAL CURRICULUM PARAMETERS \\ IN THE CONTEXT OF THE BRAZILIAN \\ EDUCATIONAL REFORM
}

Silza Maria Pasello VALENTE*

Resumo: O presente artigo tem como objeto de estudo o papel exercido pelos Parâmetros Curriculares Nacionais (PCN) no contexto da Reforma Educacional Brasileira, atendo-se a fontes documentais e bibliográficas. Inicialmente aborda o significado de Diretrizes e Parâmetros no campo da Teoria do Currículo, em seguida historiciza o surgimento do arcabouço legal dos PCN e, por fim, analisa os Parâmetros Curriculares Nacionais das Séries Iniciais e Finais do Ensino Fundamental e os do Ensino Médio.

Palavras-chave: Parâmetros Curriculares Nacionais. Ensino Fundamental. Ensino Médio.

Abstract: The aim of this article is to study the role of the National Curriculum Parameters (PCNs) in the context of the Brazilian Educational Reform, based on documental and bibliographical sources. Firstly, the meaning of Parameters and Guidelines is discussed from the Curriculum Theory standpoint. Next, the history of the legal framework of the PCNs is presented. Finally, the article presents and analysis of the National Curriculum Parameters for the first and the late series of Elementary and High Schools.

\footnotetext{
${ }^{1}$ O presente artigo é parte integrante de uma tese elaborada sob a orientação do prof. Dr. Celestino Alves da Silva Jr.: VALENTE, S.M.P. Parâmetros curriculares nacionais e avaliação nas perspectivas do Estado e da escola. (Tese de doutoramento). Universidade Estadual Paulista. Marília, SP: 2002

*Doutora em Ensino na Educação Brasileira pela UNESP. E-mail: silzavalente@uol.com.br
} 
Os parâmetros curriculares nacionais no contexto da reforma educacional brasileira

Keywords: National Curriculum Parameters. Elementary School Teaching. High School Teaching.

\section{CONSIDERAÇÕES INTRODUTÓRIAS}

Foi somente a partir do século XIX e início do século XX que, nos EUA, os problemas e questões curriculares passaram a constituirse num campo de estudos. Subjacente a esse novo campo do conhecimento estava a preocupação com os processos de racionalização, sistematização e controle da escola e do currículo. (GOODSON, 1995).

No período compreendido entre os anos 20 e o início dos anos 70 , embora outras concepções educacionais estivessem presentes, havia o predomínio, em todas as instâncias sociais, de um tipo de organização burocrática fundada na categoria weberiana da racionalidade formal, que, em termos gerais, significa a coerência entre meios e fins e se caracteriza pelo predomínio do formalismo.

Com o objetivo de formar o homem que estivesse de acordo com as necessidades de uma sociedade capitalista, impôs-se às escolas o padrão organizacional fabril. A ênfase na técnica da construção curricular, na eficácia e eficiência dos procedimentos, na preocupação com o como sem perguntar o porquê e o para que, impregnou o ambiente da educação formal, fazendo com que o currículo acabasse por ficar associado à "grade curricular" que aprisiona, submete, cerceia, estabelece regras, controla. Tal concepção privilegia a organização curricular em disciplinas e penetrou de tal maneira o espaço escolar que sua superação por outras possibilidades, apesar de desejável, é extremamente difícil.

As Diretrizes e os Parâmetros Curriculares Nacionais situam-se em um momento de transição paradigmática no campo educacional, no qual o conceito de currículo, até então vigente, não responde às necessidades postas por um presente desestabilizador e um futuro incerto. Se há alguma clareza no horizonte educacional, esta aponta para a urgência de se redefinir o papel das instituições escolares, formando pessoas para atuarem em cenários que, provavelmente, nem possam ser entrevistos.

Mundialmente, discute-se a necessidade: a) do desenvolvimento de competências, entendendo-as como mais abrangentes do que o 
domínio dos saberes disciplinares; b) do estabelecimento de diretrizes como elementos norteadores do processo de construção de projetos pedagógicos, nos quais a organização curricular é apenas um dos componentes. É nesse quadro que se insere o Brasil.

\title{
O CURRÍCULO NA PERSPECTIVA DOS PARÂMETROS CURRICULARES NACIONAIS (PCN)
}

\section{O currículo é compreendido pelos PCN como:}

\begin{abstract}
um termo muitas vezes utilizado para se referir a programas de conteúdos de cada disciplina. Mas, currículo pode significar também a expressão de princípios e metas do projeto educativo, que precisam ser flexíveis para promover discussões e reelaborações quando realizado em sala de aula, pois é o professor que traduz os princípios elencados em prática didática. Essa foi a concepção adotada nestes Parâmetros Curriculares Nacionais. (BRASIL, 1998, p.49).
\end{abstract}

Nessa concepção de currículo adotada pelos PCN dá-se destaque a atitudes de autonomia, flexibilidade, participação, responsabilidade, criatividade, que os atores sociais - equipes pedagógica e administrativa, professores, alunos e pais - responsáveis pelo fazer pedagógico deverão estar incorporando não só em termos de ideias, mas, principalmente, de ações. O difícil é a ultrapassagem da norma para a realidade escolar, pois o que se percebe é que enquanto a lei maior, no caso a Lei de Diretrizes e Bases da Educação Nacional (LDB), enfatiza a liberdade organizacional e pedagógica, a legislação decorrente expressa nos PCN não só é de difícil compreensão pelo cotidiano escolar, como estabelece uma conduta pedagógica única para todas as escolas. Portanto, a pretensa liberdade se esvai nos desvãos dos controles burocráticos que passam a ser feitos nas demais instâncias: Secretarias de Educação e Núcleos de Educação.

Todas as reformas educacionais, sem exceção, esbarraram em um obstáculo praticamente intransponível: fazer com que o discurso educacional originado nas instâncias da política de Estado venha a ser incorporado pela prática pedagógica.

Isso sucedeu com a Lei 5692/71, que reformou os ensinos de $1^{\circ}$ e $2^{\circ}$ graus e nunca foi colocada realmente em prática, a não ser 
em termos da estrutura formal, e com o Ciclo Básico, que, cerca de vinte anos depois de sua implantação no Estado do Paraná, ainda encontra resistências à incorporação do seu espírito.

Entendo que tal fato sucede pela falta de sensibilidade dos próprios legisladores, os quais, ao elaborarem o arcabouço legal, não levam em consideração a realidade das escolas - seus recursos humanos e financeiros e infraestrutura. Partem de determinados pressupostos e os generalizam, causando, com essa postura, um descompasso entre o discurso normativo e a realidade em que esse discurso deverá se efetivar.

Tanto Hernández (1998) quanto Bellini (2001) também incluem tal perspectiva em suas análises: o primeiro, enfocando as condições de trabalho e salariais; a segunda, enfatizando a dimensão cultural. Afirmam os autores:

Por tudo observado no Brasil, e que é extensivo à boa parte dos países da América Latina que está neste momento enfrentando reformas educativas, não se pode falar em mudar a Escola se ela não tem uma série de condições materiais e de recursos que permitam realizar, com dignidade, o trabalho docente, e sem que os professores recebam um salário justo por seu trabalho. (HERNÁNDEZ, 1998, p.10).

A nova LDB ou tantas teorias pedagógicas básicas são importantes, mas não são suficientes para mudar a cultura e o fazer pedagógico; a lei e as teorias são apenas bases para o começo de uma desconstrução da cultura autoritária que cada um de nós assumiu como brasileira nestes 500 anos de subordinação e destruição de identidades [...] Trata-se de, como diz Gambini, ir além da espera, não se trata de atribuir a tarefa educacional à política, à economia, à LDB [...], mas de 'sairmos da maldição de não podermos ser aquilo que potencialmente somos'. Tarefa psíquica e cultural. (BELLINI, 2001, p.5-6).

Guiomar Namo de Mello, no Parecer CEB 15/98, faz uma elucidativa distinção entre as Diretrizes estabelecidas pela LDB e as Diretrizes deliberadas pelo Conselho Nacional de Educação (CNE). Segundo a Relatora, as primeiras, que se referem à organização da educação nacional definindo seu norte, sua direção, são diretrizes mais duradouras. Ainda que sejam passíveis de revisão, esta depen- 
de de uma articulação da sociedade e de aprovação pelo Congresso Nacional. As diretrizes deliberadas pelo CNE são mais próximas do universo pedagógico, do fazer das instituições escolares; configuramse como indicações para um acordo entre os diferentes parceiros - união, unidades federativas, instituições escolares, professores - sendo, portanto, passíveis de revisões e atualizações mais frequentes. Resumindo, quanto mais próximos da área de aplicação, mais flexíveis são os procedimentos. No entanto, como pode se detectar nas falas transcritas, essa pseudoflexibilidade esbarra nas exigências burocráticas que provocam um engessamento das práticas escolares, enquadrando-as em modelitos pré-determinados.

Analisando os documentos relativos às Diretrizes e aos PCN, em muitos momentos fui tomada por dúvidas: primeiramente, porque não há uma seqüência lógica na elaboração dos mesmos; segundo, porque imperava, a cada momento, a sensação de que, no interior do MEC, não houve diálogo entre as equipes responsáveis pela elaboração do Referencial para a Educação Infantil, dos PCN do Ensino Fundamental e dos PCN do Ensino Médio.

Em relação às Diretrizes, entendo que sendo as balizadoras do processo pedagógico, deveriam preceder os Parâmetros. Isso sucede em relação aos PCN do Ensino Médio. No entanto, o Referencial Curricular para a Educação Infantil e os PCN do Ensino Fundamental foram, primeiramente, elaborados pelo MEC e, posteriormente, encaminhados ao Conselho Nacional de Educação (CNE), que, após análise e parecer, elaborou as Diretrizes Curriculares Nacionais para a Educação Infantil (Resolução CEB nº.1, de 7 de abril de 1999) e as Diretrizes Curriculares para o Ensino Fundamental (Resolução CEB $\mathrm{n}^{\circ}$. 2, de 7 de abril de 1998).

Os PCN do Ensino Fundamental referentes aos dois primeiros Ciclos $\left(1^{\mathrm{a}} / 2^{\mathrm{a}}\right.$ e $3^{\mathrm{a}} / 4^{\mathrm{a}}$ séries) foram os primeiros a serem elaborados. Conforme relatório constante do Parecer CEB 3/97, em 19 de setembro de 1996 o Ministro de Estado da Educação e do Desporto, Professor Paulo Renato de Souza, encaminhou ao CNE o documento intitulado "Parâmetros Curriculares Nacionais" (referente aos dois primeiros Ciclos ou às quatro primeiras séries), solicitando a devida apreciação desse documento pelo Colegiado competente.

O referido Parecer ressalta a importância do documento em tela (note-se que foi encaminhado antes da aprovação da nova LDB, que viria a ocorrer somente três meses após) e faz um breve histórico 
da sua trajetória. Nesse histórico destaca que, já em 1995, antes da criação do CNE, a Secretaria do Ensino Fundamental (MEC), com o intuito de provocar uma ampla discussão, havia divulgado para todo o país a primeira versão dos Parâmetros. Essa proposta foi elaborada por professores em exercício no Ensino Fundamental, especialmente contratados para tal finalidade, os quais contaram com a assessoria de professores especialistas.

Embora o Parecer não mencione os componentes das equipes de professores, nem nomine os consultores, afirma-se que os PCN foram "aparentemente idealizados e redigidos por um pequeno grupo de professores vinculados a uma escola privada da cidade de São Paulo". Informa-se, também, que "para assessorar o grupo responsável pela elaboração dos PCN e seus próprios técnicos, o MEC contratou os serviços dos professores espanhóis César Coll e Anna Teberosky". (SILVA JÚNIOR, 1998, p.89).

Comentando a respeito da consultoria prestada por César Coll, Moreira (1997) aponta a influência exercida pelo consultor na incorporação, pela Reforma Brasileira, das ideias inspiradoras da Reforma Espanhola. Tais ideias foram claramente evidenciadas na prevalência da Psicologia como fonte privilegiada na definição dos objetivos e conteúdos e na elaboração do plano de ação a ser seguido na educação escolar, assim como na concepção de currículo incorporada pelos PCN.

O referido autor critica, duramente, tanto a predominância da Psicologia no desenho curricular proposto por Coll, como sua concepção de currículo, que expressa uma postura tradicional, direcionadora, a-histórica, minimizadora das questões políticas e ideológicas, desconsiderando as contribuições e questionamentos da Sociologia do Currículo.

O documento foi encaminhado a cerca de 400 consultores: professores universitários, especialistas das diferentes áreas e representantes das principais associações científicas ligadas à educação. A eles foram solicitados pareceres, tanto a respeito do documento em geral quanto da área de conhecimento pertinente à formação do consultor. Simultaneamente, o MEC, através das suas Delegacias Estaduais, promoveu reuniões com os professores, a fim de dar conhecimento e provocar debates sobre os PCN.

Segundo o Parecer em questão, essas discussões apresentaram duas reservas, consideradas como principais. Ambas recriminaram a 
falta de participação, nas equipes, de especialistas e pesquisadores da área de currículo e a ausência de consulta prévia ao público alvo. Os relatores do Parecer contrapõem-se da seguinte forma: a falta de participação dos especialistas em currículo foi suprida com o envio do documento aos consultores, os quais encaminharam ao MEC cerca de 700 pareceres apresentando sugestões, muitas das quais foram incorporadas aos PCN; a alegação da falta de participação dos professores não se justificou, porque as equipes contavam com esses profissionais em efetiva atuação nesse nível de ensino.

Dando continuidade ao exposto, os conselheiros afirmam que o CNE não esperou que os PCN lhe fossem oficialmente entregues, para deles tomar conhecimento. Além de vários dos conselheiros atuarem como consultores na elaboração dos PCN, o próprio CNE realizou seminários regionais com o intuito de discutir os Parâmetros, em colaboração com os Conselhos Estaduais e Municipais de Educação, além das Secretarias de Educação dos Estados e Municípios sedes dos eventos. Além disso, os PCN foram analisados e discutidos internamente pelos membros do Conselho.

Ao analisarem o teor do documento encaminhado ao CNE, ou seja, a versão de agosto de 1996 dos PCN, os Conselheiros Relatores Edla de Araújo Lira Soares, Fábio Luiz Marinho Aidar, Hermengarda Alves Ludke e Regina Alcântara de Assis assim se manifestaram:

1. Os PCN apresentam princípios educativos e uma proposta de articulação entre objetivos, conteúdos, orientações didáticas e critérios de avaliação, buscando contribuir para o aperfeiçoamento da prática pedagógica, sem criar novas disciplinas ou se revestir de caráter de obrigatoriedade.

2. Os PCN, como referencial nacional, apontam para um horizonte de aperfeiçoamento da qualidade no ensino fundamental, e sua aplicação pressupõe o "pluralismo de idéias e de concepções pedagógicas" e a gestão curricular autônoma, tanto das Secretarias Estaduais e Municipais, quanto das escolas, respeitando, desta forma, a estrutura federativa do País. Ao serem utilizados, deverão estimular o desenvolvimento do projeto educativo de cada escola e envolver a atuação dos professores e das equipes pedagógicas das Secretarias de Educação e das unidades escolares, não apenas na discussão e redefinição curricular, como também incorporando as experiências diferenciadas da população em respeito à pluralidade cultural brasileira. 
Os parâmetros curriculares nacionais no contexto da reforma educacional brasileira

3. Os PCN resultam de uma ação legítima, de competência privativa do MEC, e se constituem em uma proposição pedagógica, sem caráter obrigatório, que visa à melhoria da qualidade do ensino fundamental e o desenvolvimento profissional do professor. É nesta perspectiva que devem ser apresentados às Secretarias Estaduais, Municipais e às Escolas.

4. Os PCN não dispensam a necessidade de formulação de diretrizes curriculares nacionais, que deverão fundamentar a fixação de conteúdos mínimos e a base nacional comum dos currículos, em caráter obrigatório para todo o território nacional, nos termos do artigo 26 da Lei 9394/96 (LDB).

Tendo em vista os dispositivos constitucionais e legais pertinentes, a CEB exercitará a sua função deliberativa, formulando as Diretrizes Curriculares Nacionais (DCN). Ainda no exercício de sua competência, ao MEC caberá a avaliação permanente e a revisão periódica dos Parâmetros Curriculares Nacionais para o Ensino Médio. É o nosso voto.

Embora longo, é importante conhecer o Voto do Relator, porque explicita, claramente, não só o posicionamento favorável do CNE a respeito dos PCN, como o entendimento do Conselho de que as Diretrizes devem ser estabelecidas a posteriori. Isso configura, a meu ver, uma inversão lógica: as diretrizes passaram a ser depreendidas dos Parâmetros, ao invés de se constituírem em balizadoras para sua elaboração.

Se nos voltarmos para a dimensão “tempo", essa inversão lógica fica ainda mais evidente, uma vez que:

- o primeiro Parecer sobre os PCN é datado de 12 de março de 1997;

- os PCN referentes às quatro primeiras séries do Ensino Fundamental foram publicados em 1997 e os de $5^{a}$ a $8^{a}$ em 1998, enquanto que as Diretrizes do Ensino Fundamental foram publicadas em 7 de abril de 1998;

- o Referencial Curricular para a Educação Infantil foi publicado em 1998, enquanto que a publicação das Diretrizes Curriculares para a Educação Infantil ocorreu somente em 7 de abril de 1999.

Olhar de professor, Ponta Grossa, 12(2): 233-256, 2009 Disponível em <http://www.uepg.br/olhardeprofessor> 
É plausível deduzir de tal situação que, tendo as escolas recebido o Referencial para a Educação Infantil e os Parâmetros do Ensino Fundamental entre 1997 e 1998 (segundo o Ministro, cada professor deveria receber um exemplar) e começado a lê-los e discuti-los, o fizeram sem ser à luz das Diretrizes, pois essas somente foram formalizadas em 1998 e 1999. Além disto, ao fornecerem os indicadores para a elaboração dos projetos educativos, os referidos documentos não mencionam as Diretrizes, como se não devessem fazer parte do universo de discussões e reflexões.

Segundo explicitado no documento introdutório dos PCN de $1^{\mathrm{a}}$ a $4^{\mathrm{a}}$, os Parâmetros Curriculares Nacionais não têm a pretensão de estabelecer um currículo nacional obrigatório, mas de garantir que haja uma base nacional de formação comum a todos aqueles que cursam a Educação Básica. Respeitam a autonomia de cada unidade da federação e de cada escola, propiciando que tenham uma margem de liberdade para agir, visto que preveem uma Parte Diversificada, com o fito de atender às necessidades regionais e locais.

No entanto, eu ousaria dizer que propiciam uma liberdade vigiada, dada a existência de mecanismos de controle exercidos pela submissão dos livros didáticos aos PCN e a realização de processos avaliativos de larga escala, que têm o objetivo de avaliar a Parte Comum. Não é por acaso que o SAEB antecedeu, e muito, a elaboração dos PCN. Na verdade, como afirma Silva Júnior (1998, p.89), no caso brasileiro, "a avaliação antecede o currículo que deveria estabelecer os critérios para sua efetivação".

Não se pode deixar de levar em consideração a ênfase que tem sido dada, a partir da década de oitenta, aos processos avaliativos externos, assim como não se pode negar a sua importância no sentido de propiciar o aperfeiçoamento do Sistema Educacional.

O que pode e deve ser questionado é o conteúdo da avaliação e a discussão dos seus resultados no cotidiano escolar. Até que ponto as avaliações realizadas aprisionam a escola ou possibilitam avanços? Qual a repercussão das avaliações de larga escala no cotidiano escolar? Até que ponto as avaliações têm contribuído para melhorar a qualidade do ensino? Como os resultados das avaliações têm se traduzido na política de capacitação docente e na transformação das condições de trabalho nas escolas públicas?

Os PCN situam-se no contexto de atendimento ao dispositivo constitucional expresso no Art. 210 da Constituição de 1988: "Serão 
Os parâmetros curriculares nacionais no contexto da reforma educacional brasileira

fixados conteúdos mínimos para o Ensino Fundamental de maneira a assegurar formação básica comum e respeito aos valores culturais e artísticos, nacionais e regionais". Em seu Art. $9^{\circ}$, inciso IV, a LDB esclarece que a União incumbir-se-á de:

estabelecer, em colaboração com os Estados, o Distrito Federal e os Municípios, competências e diretrizes para a educação infantil, o ensino fundamental e o ensino médio, que nortearão os currículos e seus conteúdos mínimos, de modo a assegurar formação básica comum.

A LDB, portanto, além de indicar os parceiros para o estabelecimento das competências e diretrizes, amplia o conceito de formação básica comum, acrescentando o Ensino Médio, que falta ao texto constitucional.

Em face dessa alocução, como fica o MEC antecipando-se na elaboração dos Parâmetros Curriculares Nacionais que viriam a ser reconhecidos como definidores da formação básica comum?

O Ministro da Educação, fazendo uma análise dos feitos de sua primeira gestão e reconhecendo esse fato, assim o explica:

Percebo como algo também muito importante que foi feito nesse período a definição dos parâmetros curriculares nacionais.

Tínhamos uma situação paradoxal em que, obviamente, a responsabilidade constitucional e legal pela definição dos currículos é dos estados ou dos municípios. Não tínhamos responsabilidade legal pela definição de um parâmetro nacional. Não deve haver pela própria organização jurídica de nosso país um currículo nacional. Mas sentíamos a necessidade de ter um referencial nacional, até mesmo para poder avaliar um livro didático, porque na ausência de um referencial nacional, na verdade, o livro mais vendido passará a ser o currículo nacional, e o que fizemos foi, portanto, definir parâmetros curriculares. (SOUZA, 1999, p.22).

Da fala do Ministro depreende-se, portanto, que a primeira preocupação, ao se definirem os Parâmetros, foi com o estabelecimento de referenciais para a avaliação do livro didático, como explicitado. Mas se pode inferir, também, que o SAEB foi beneficiado.

Além dos explicitados, outro aspecto que chama a atenção na fala do Ministro é a atitude pendular: ora parâmetros, ora currículo 
nacional. Como bem apontou a Faculdade de Educação da Universidade Federal do Rio Grande do Sul (1996), o que se estabeleceu, dada a minuciosidade dos documentos, foi muito mais um Currículo Nacional do que parâmetros curriculares, os quais, pela sua índole, deveriam apenas fornecer indicadores gerais.

\section{PARÂMETROS CURRICULARES NACIONAIS DOS CICLOS/ SÉRIES INICIAIS DO ENSINO FUNDAMENTAL}

Os PCN do Ensino Fundamental privilegiam a organização curricular em ciclos, incorporando uma postura pedagógica que foi introduzida no universo educacional na década de oitenta.

Assumir a perspectiva da organização curricular em ciclos significa imprimir ao currículo um caráter processual, evitando a organização seriada, condizente com uma conduta pedagógica mais afeita à reprovação do que à incorporação. No entanto, considero que fica difícil, ao professor, romper com o estabelecido e já tão sedimentado paradigma seriado, quando a própria organização em ciclos prevê que cada um deles compreende dois anos e que, ao final, o aluno deve demonstrar que atingiu os critérios de avaliação estabelecidos.

Pelo que tenho observado, as escolas dividem os ciclos de dois anos em fases 1,2/3, 4. Quando o aluno não atinge o que foi previsto para cada uma delas fica reprovado, embora, através de artifícios administrativos, seja virtualmente localizado na fase posterior. Isso se dá porque os agrupamentos são fixos, ou seja, os alunos pertencem à fase (ou série) e não ao grupo.

Entendo que a ruptura poderia ser mais efetiva, se a organização curricular fosse feita em módulos, com ênfase nos objetivos, especialmente nas Séries Iniciais, e se os alunos fossem agrupados segundo o alcance dos objetivos. Essa opção exige uma transgressão daquilo que se faz habitualmente nas escolas, em termos de organização do trabalho, com cada professor sendo responsável por uma fase ou série.

Tal contradição pode ser apreendida nos próprios documentos da Reforma, pois os PCN referentes às quatro primeiras séries do Ensino Fundamental oscilam entre a organização em ciclos, que é privilegiada no interior dos documentos, e a alocução introdutória de responsabilidade do Ministro da Educação, o qual afirma, dirigindo-se ao Professor: "É com alegria que colocamos em suas mãos os Parâme- 
Os parâmetros curriculares nacionais no contexto da reforma educacional brasileira

tros Curriculares Nacionais referentes às quatro primeiras séries da Educação Fundamental.” (BRASIL, 1997, p.5, grifos meus).

O Ministro, em sua alocução, faz algumas afirmações sobremaneira importantes: a) o objetivo do Ministério, ao consolidar os Parâmetros, foi o de "apontar metas de qualidade que ajudem o aluno a enfrentar o mundo atual como cidadão participativo, reflexivo e autônomo, conhecedor dos seus direitos e deveres"; b) os Parâmetros "foram elaborados de modo a servir de referencial para o trabalho do professor, respeitando a sua concepção pedagógica própria".

Nessa fala do Ministro, é importante destacar não só a referência a séries, ao invés de ciclos, como o fato de se usar uma terminologia que está em desacordo com a LDB: educação, no lugar de Ensino Fundamental. Isso porque as palavras utilizadas podem induzir os leitores a muitas interpretações. Uma das possíveis leituras é a de que séries e ciclos são vistos da mesma forma pelo MEC, quando, na verdade, possuem naturezas opostas. Como enfatizado por Umberto Eco, em "O Nome da Rosa", é infinito o poder da palavra, portanto o MEC deveria ser mais cuidadoso, principalmente porque os PCN pretendem um rompimento paradigmático.

Além disso, apesar de o ministro afirmar que os Parâmetros devem apenas servir de referencial, visto que respeitam a concepção pedagógica do professor, não é o que se depreende da leitura dos documentos. Como se pode constatar, os PCN estão comprometidos com uma determinada concepção pedagógica que lhes presta coerência interna. Neles está claramente explicitada a sua abordagem teórico-metodológica:

A orientação proposta nos PCN reconhece a importância da participação construtiva do aluno e, ao mesmo tempo, da intervenção do professor para a aprendizagem de conteúdos específicos que favoreçam o desenvolvimento das capacidades necessárias à formação do indivíduo. Ao contrário de uma concepção de ensino e aprendizagem como um processo que se desenvolve por etapas, em que a cada uma delas o conhecimento é "acabado", o que se propõe é uma visão da complexidade e da provisoriedade do conhecimento. De um lado, porque o objeto de conhecimento é 'complexo' de fato e reduzi-lo seria falsificá-lo; de outro, porque o processo cognitivo não acontece por justaposição, senão por reorganização do conhecimento. É também 'provisório', uma vez que não é possível chegar de imediato ao conhecimento correto, 
mas somente por aproximações sucessivas que permitem sua reconstrução. (BRASIL, 1997, p.44).

Esse comprometimento dos PCN com uma determinada concepção do processo ensino e aprendizagem praticamente obriga os professores a segui-los na íntegra, sob pena de, ao não fazê-lo, comprometer a coerência de suas ações pedagógicas. Tal perspectiva está claramente explicada nos PCN de Língua Portuguesa referentes às quatro primeiras séries:

[...] não tem sentido utilizar os critérios indicados neste documento para avaliar a aprendizagem de alunos submetidos a práticas educativas orientadas por outros objetivos (que não os aqui especificados). A adoção desses critérios pressupõe a adoção também dos objetivos propostos neste documento e às adaptações dos objetivos que cada equipe escolar julgar necessárias precisam corresponder adaptações também dos critérios. (BRASIL, 1997, p.95).

Os PCN são comprometidos com uma concepção de ensino e aprendizagem que está de acordo com o paradigma educacional emergente, que é construtivista, interacionista, sociocultural e transcendente. Moraes (1997) interpreta esse paradigma como o modelo educacional coerente com as produções teóricas atuais, relativas às mais variadas áreas do conhecimento, e que deve se constituir no ethos das práticas educativas escolares. Como diz Rios (2001, p.21), “cada sociedade possui seu ethos, ou se compõe de um conjunto de ethos, jeitos de ser, que conferem um caráter àquela organização social".

O referido paradigma concebe que o pensamento não tem fronteiras e que se constrói e reconstrói ao sabor das vivências/experiências; que o processo de construção do conhecimento depende das interações que o aprendente estabelece com o meio cultural, com os outros e com os objetos do conhecimento; que aprender é construir significados acerca dos conteúdos curriculares; que o saber está em permanente construção, é transitório e dependente do estado atual do conhecimento; que o processo de aprendizagem deve levar o indivíduo a superar seus limites e limitações, a compreender-se como parte de um todo que, em última instância, é a própria humanidade.

Nessa perspectiva, a construção do conhecimento tem caráter de processo em permanente elaboração. Assim, cabe ao professor exercer papéis condizentes muito mais com as posturas de orientador, 
Os parâmetros curriculares nacionais no contexto da reforma educacional brasileira

mediador e desafiador, que de direcionador, embora não deva furtarse em assumir esta última, quando necessário.

Essa compreensão do processo de ensino e aprendizagem leva ao entendimento, nos PCN, de uma prática avaliativa essencialmente formativa, em que os desempenhos são avaliados em função de critérios de aprendizagem previamente definidos e analisados. Deve-se ter em mente o que se faz necessário para que o aprendente seja capaz de executar determinadas tarefas julgadas essenciais como resultados de aprendizagens.

Esse entendimento permite-me, ainda, deduzir que, na ótica formativa, a avaliação deve partir da realidade e a ela retornar para transformá-la. Se isto não acontecer, não poderá ser considerada como tal e sua razão de ser terá deixado de existir.

Sob a égide dessa perspectiva formativa postula-se, nos PCN, que os conteúdos de aprendizagem sejam entrevistos em uma dimensão que transcenda o vivenciado até então pelas escolas, ou seja, que os conteúdos: a) não permaneçam sendo vistos como fins em si mesmos, mas como um meio para os alunos desenvolverem as capacidades que lhes permitam produzir bens culturais, sociais e econômicos e deles usufruir; b) contemplem as seguintes dimensões: conceitual, procedimental e atitudinal.

A dimensão conceitual abrange conhecimentos que ensejem aos alunos desenvolver as capacidades cognitivas para possibilitar-lhes operar com símbolos, ideias, imagens, representações que permitem organizar a realidade. Envolve fatos, conceitos, princípios. Consiste, portanto, no plano do saber.

A dimensão procedimental abrange conhecimentos que ensejem aos alunos desenvolver as capacidades cognitivas que lhes possibilitem tomar decisões e realizar ações de forma ordenada e não aleatória para atingir uma meta. Envolve, portanto, não só a aprendizagem como a realização de ações, e consiste no plano do fazer.

A dimensão atitudinal permeia todo o conhecimento escolar, à medida que compreende valores, atitudes, normas, hábitos. Consiste nos planos do ser e do conviver. Embora essencial, é uma dimensão raramente contemplada pelas escolas, peormanecendo muito mais no plano do implícito - currículo oculto - do que no plano do explícito. Considerar essa dimensão como parte dos conteúdos escolares faz com que ela passe a ter visibilidade e a ser discutida pelo coletivo das escolas. 
É evidente que, em sintonia com os conteúdos e direcionadores, tanto deles quanto das orientações didáticas e dos procedimentos e critérios de avaliação, os objetivos também contemplam essas mesmas dimensões.

Tendo como norte o pressuposto de que os alunos devem desenvolver as capacidades expressas nos objetivos do Ensino Fundamental e nos da área e do ciclo, assim como naqueles constantes no Projeto Educativo da escola e em seu próprio planejamento, o professor deverá propiciar-lhes experiências de aprendizagem que possibilitem o desenvolvimento das diferentes capacidades.

Com a finalidade de superar uma organização curricular centrada em disciplinas, amparada em um processo de construção do conhecimento estanque, positivista, não dialógico, os PCN optaram pela organização curricular em áreas do conhecimento, esclarecendo que:

Nos Parâmetros Curriculares Nacionais, a opção do termo 'área' deu-se em função de que, no ensino fundamental, um tratamento disciplinar, entendido como preponderantemente lógico e formal, distancia-se das possibilidades de aprendizagem da grande maioria dos alunos. Além disso, parte-se de abordagens mais amplas em direção às mais específicas e particulares. O tratamento dos conteúdos deve integrar conhecimentos de diferentes disciplinas, que contribuem para a construção de instrumentos de compreensão e intervenção na realidade em que vivem os alunos. (BRASIL, 1998, p.58).

No entanto, as áreas continuaram com a mesma denominação das disciplinas, as quais permaneceram proporcionando a fundamentação epistemológica e servindo como eixo organizador da hierarquização e estruturação dos conteúdos, como se pode verificar na leitura dos PCN.

Considero que o fato de as áreas permanecerem contemplando a mesma nomenclatura das disciplinas seja um impeditivo para a superação do paradigma disciplinar e para o uso de uma postura dialógica e interdisciplinar, exigida pelos Temas Transversais. Este, aliás, constitui-se em um dos aspectos mais polêmicos dos PCN, não só no Brasil como na Espanha, nossa fonte inspiradora. A impressão que se tem é a de que o possível avanço a ser proporcionado pelos Temas Transversais esbarra em uma organização curricular que os 
Os parâmetros curriculares nacionais no contexto da reforma educacional brasileira

privilegia perifericamente, imputando-lhes um destino de capilaridade difícil de ser realizado.

Outorga-se aos Temas Transversais, nos PCN, a tarefa de trazer para dentro da escola questões sociais, culturais, ecológicas, éticas, geralmente desprezadas pelas disciplinas tradicionais. Ao mesmo tempo, lhes é dada a tarefa de aglutinar as diferentes áreas em torno de temas que lhes permitam estabelecer diálogos e objetivos comuns. Embora eu reconheça, a exemplo de Yus (1998, p.18), que os "temas transversais trazem ar fresco à velha escola tipo século XIX", não olvido que as condições de trabalho de nossos professores comprometem a possibilidade de oxigenação curricular, a qual necessita de condições mais condizentes com as novas exigências educacionais: autonomia, flexibilidade, criatividade. Não há transversalidade sem diálogo, nem diálogo sem tempo, nem tempo sem condições propícias de trabalho.

\section{PARÂMETROS CURRICULARES NACIONAIS DAS SÉRIES FINAIS DO ENSINO FUNDAMENTAL}

Os Parâmetros Curriculares de $5^{\mathrm{a}}$ a $8^{\mathrm{a}}$ Séries contemplam, basicamente, a mesma estrutura dos parâmetros das Séries Iniciais. $\mathrm{Na}$ alocução dirigida "Ao Professor", o Ministro passa a utilizar a nomenclatura correta - "Ensino Fundamental"-, mas continua mencionando séries, em vez de ciclos. Nesse texto ele não faz referência à liberdade de postura pedagógica, levando a supor que o MEC tenha se dado conta da incoerência de tal afirmativa.

Ao ler a Apresentação, chamou-me a atenção o fato de que, enquanto os PCN das Séries Iniciais eram colocados à disposição somente do professor e da escola, nos PCN das séries finais o leque de interessados se amplia: Secretarias de Educação, escolas, instituições formadoras de professores, instituições de pesquisa, editoras e todas as pessoas interessadas em educação são explicitamente indicadas como interlocutores/utilizadores.

No caso específico das secretarias municipais de educação, devido ao processo de municipalização da Educação Infantil e das Séries Iniciais, é de se supor que essas secretarias não foram mencionadas nos PCN das Séries Iniciais. O mesmo não sucede com as secretarias estaduais, consideradas interlocutoras privilegiadas. Daí sua inclusão nos PCN das séries finais. 


\section{PARÂMETROS CURRICULARES NACIONAIS DO ENSINO MÉDIO}

Os Parâmetros Curriculares do Ensino Médio possuem uma lógica diversa dos seus antecessores. Foram editados em um único volume, que contempla a Lei de Diretrizes e Bases da Educação Nacional; o Parecer CEB 15/98, de autoria de Guiomar Namo de Mello, que analisa o documento com "propostas de regulamentação da base curricular nacional e de organização do Ensino Médio", elaborado pelo MEC e encaminhado pelo Ministro ao CNE; a Resolução CEB n.3, de 26 de junho de 1998, que institui as Diretrizes Curriculares para o Ensino Médio; e os Parâmetros Curriculares do Ensino Médio, oficialmente lançados em 15 de outubro de 1999, durante o I Seminário do Exame Nacional do Ensino Médio, realizado em Brasília, no período de 13 a 15 de outubro de 1999.

Essa forma de publicação dos documentos relativos ao Ensino Médio produz uma lógica de ação diversa daquela possibilitada pelos PCN do Ensino Fundamental. Ao terem em mãos os referidos documentos, os professores do Ensino Médio possuem um leque analítico-interpretativo muito mais amplo e diferenciado. Com eles podem perceber como a LDB, as Diretrizes do Ensino Médio e os Parâmetros se entrelaçam, além de poderem tomar conhecimento do Parecer elaborado por Guiomar Namo de Mello, que analisa o significado do Ensino Médio no Sistema Educacional Brasileiro e fornece o suporte teórico-metodológico que fundamenta suas Diretrizes.

Embora tenham sido lançados oficialmente na data aludida, os PCN do Ensino Médio já estavam sendo discutidos e, mesmo, sendo objeto de amparo para reorganizações curriculares nos Estados de São Paulo - como foi evidenciado em artigo que analisa as Resoluções da Secretaria de Educação do Estado de São Paulo datadas de 19/01/98 e 23/01/98, referentes à reorganização curricular dos cursos de Ensino Médio (FERNANDES, 1999) - e do Paraná. Neste Estado essa discussão e reorganização curricular foram desenvolvidas principalmente através do Programa Expansão, Melhoria e Inovação no Ensino Médio do Paraná (PROEM), assinado em 1997 e implementado no período 1998-2002, conforme consta no informativo governamental Dez Anos de Educação no Paraná. (PARANÁ, 2001).

Ao relatar o processo de construção do projeto de reforma curricular do Ensino Médio, a Secretaria de Educação Média e Tecno- 
Os parâmetros curriculares nacionais no contexto da reforma educacional brasileira

lógica informa que foram envolvidos nesse processo, e mantiveram permanente diálogo, os dirigentes da referida Secretaria, a equipe técnica coordenadora do projeto e os diversos setores da sociedade civil, ligados direta ou indiretamente à educação, além de professores e técnicos dos diferentes níveis de ensino.

A proposta elaborada foi, em inúmeras ocasiões e por diferentes e vários atores, amplamente discutida, obtendo altos níveis de aceitação. Os trabalhos foram concluídos em junho de 1997, e o documento produzido foi apresentado aos Secretários de Educação das Unidades Federadas e encaminhado ao Conselho Nacional de Educação. Um ano após, o CNE emitiu o Parecer que deu sustentação à Resolução CEB nº. 3, de 26 de junho de 1998, para estabelecer as Diretrizes do Ensino Médio.

Tendo como norte o Parecer e a Resolução editados pelo CNE, o MEC fez nova análise de sua proposta e elaborou a versão definitiva dos Parâmetros Curriculares do Ensino Médio, a qual foi dada ao conhecimento público em 15 de outubro de 1999.

As Diretrizes do Ensino Médio estabelecem os princípios da Identidade, Diversidade, Autonomia, Interdisciplinaridade e Contextualização como estruturadores do currículo (Art. $6^{\circ}$ ). A liberdade, a autonomia, a flexibilidade e a criatividade são por elas estimuladas e amparadas no arcabouço legal. Além disso, as Diretrizes propõem a realização de experiências de organizações curriculares não convencionais; o uso de outras possibilidades de tempo e espaço; o estabelecimento de parcerias e articulações com instituições públicas e privadas, contemplando a preparação para o trabalho; o diálogo intra e entre as áreas de conhecimento; o desenvolvimento de projetos de investigação e/ou ação; a preparação para o exercício pleno da cidadania e para a inserção no mundo do trabalho; a relação teoriaprática e a aprendizagem significativa.

A base nacional dos currículos do Ensino Médio (Art. 10) é organizada nas seguintes áreas de conhecimento: Linguagens, Códigos e suas Tecnologias; Ciências da Natureza, Matemática e suas Tecnologias, Ciências Humanas e suas Tecnologias.

Diferentemente dos PCN do Ensino Fundamental, que mantiveram a mesma nomenclatura das disciplinas ao nomear as áreas, as Diretrizes do Ensino Médio determinam somente as áreas, sem fazer menção às disciplinas, definindo, para cada uma delas, competências e habilidades, em vez de objetivos. Preceituam, também, que 
a interdisciplinaridade e a contextualização devem ser asseguradas pelas propostas pedagógicas, e introduzem Filosofia e Sociologia como componentes curriculares obrigatórios, atendendo ao disposto no Art.36, $\$ 1^{\circ}$, inciso III, da LDB.

Os Parâmetros Curriculares do Ensino Médio foram organizados de forma a contemplar, inicialmente, as Bases Legais desse nível de ensino (Parte I). Em seguida, após apresentar uma visão de cara área e de suas disciplinas potenciais, eles estabelecem uma reflexão teórica e prática sobre as competências e habilidades que devem ser desenvolvidas pelos alunos nas diferentes áreas (Partes II, III e IV). No final das partes referentes às três áreas, os Parâmetros expõem um quadro em que as competências e habilidades de cada área estão organizadas em torno de três eixos: Representação e Comunicação, Investigação e Compreensão, e Contextualização Sócio-Cultural. Embora seja possível deduzir que se trata de uma matriz, não há no documento nenhuma explicação a respeito.

A mesma estrutura se repete com relação às disciplinas que fazem parte de cada uma das áreas, a saber:

- Área de Linguagens, Códigos e suas Tecnologias: Língua Portuguesa, Língua Estrangeira Moderna, Educação Física, Arte, Informática. - Área de Ciências da Natureza, Matemática e suas Tecnologias: Biologia, Física, Química, Matemática.

- Área de Ciências Humanas e suas Tecnologias: História, Geografia, Sociologia, Antropologia e Política, Filosofia.

Os PCN do Ensino Médio diferem radicalmente, em termos de organização, dos demais parâmetros. Estabelecem competências e habilidades em vez de objetivos; não definem os conteúdos, afirmando que essa definição deverá ser realizada nos demais níveis (Proposta Curricular de cada Unidade da Federação e Propostas Pedagógicas das Escolas), à luz das competências e habilidades; fornecem orientações metodológicas de forma abrangente e não se detêm nos aspectos relativos à avaliação da aprendizagem, embora estes sejam cruciais para sua efetivação. Também não contemplam os Temas Transversais. Presumo que as questões culturais, sociais, éticas e do mundo do trabalho deverão ser incorporadas às áreas como conteúdos programáticos.

Um ponto a ser destacado é o referente aos níveis de operacionalização dos PCN, que, nos documentos em tela, são definidos na seguinte sequência: MEC $\rightarrow$ Secretarias da Educação Estaduais 
Os parâmetros curriculares nacionais no contexto da reforma educacional brasileira

ou Municipais $\rightarrow$ Projetos Educativos ou Propostas Pedagógicas das Escolas $\rightarrow$ Planejamento do Professor. Nessa sequência de operacionalização, os PCN teriam a possibilidade de irem se afunilando e adquirindo feições mais particularizadas com a introdução dos conteúdos que venham a contemplar necessidades regionais e locais. Cabe identificar qual tem sido a atuação das Secretarias de Educação Estaduais e Municipais, nesse sentido.

\section{CONSIDERAÇÕES FINAIS}

São diversos e, muitas vezes, contraditórios os significados propiciados pelo arcabouço normativo da Reforma Educacional Brasileira. E, talvez, uma das maiores contradições normativas seja a estabelecida entre liberdade e flexibilidade, propiciada pela LDB, e a postura diretiva dos Parâmetros Curriculares Nacionais. Enquanto a lei maior aponta para um horizonte repleto de possibilidades no que diz respeito a espaço, tempo, forma de organização, pluralidade de ideias, os Parâmetros determinam o que, como e quando se deve fazer. Condicionam a avaliação da aprendizagem e os conteúdos, apontam o que deve ser ensinado, determinando tempos e modos de agir.

E aí adentramos o espaço da segunda contradição normativa: sendo tão prescritivos e direcionadores, os PCN não se configuram propriamente como parâmetros, como padrões que orientam ou subsidiam a ação educativa. Na realidade, eles constituem um Currículo Nacional, acabando por cercear a autonomia, a criatividade, a flexibilidade e a liberdade de opção pedagógica que apregoam (mesmo porque estabelecem as regras para a elaboração dos livros didáticos e para o Sistema Nacional de Avaliação da Educação Básica - SAEB). Esse é um alerta que os responsáveis pela análise do documento Parâmetros Curriculares Nacionais ${ }^{2}$ já haviam feito:

Embora o documento afirme que não se trata do estabelecimento de um Currículo Nacional, mas de parâmetros curriculares supostamente flexíveis e não obrigatórios, parece evidente que a explicitação detalhada feita nos documentos parciais que o compõem, assim como as condições sob as quais está sendo feita sua implantação, apontam, na verdade para o contrário disso. (UFRGS/FE, 1996, p.127).

${ }^{2}$ Essa análise foi efetivada pela Faculdade de Educação da Universidade Federal do Rio Grande do Sul, uma das instituições de Ensino Superior que, por solicitação do MEC, examinaram a versão preliminar dos Parâmetros Curriculares Nacionais. 
Aponto, ainda, como elementos contraditórios depreendidos das normas o fato de usarem indistintamente a terminologia séries e ciclos, quando, no que se refere à organização curricular e concepção pedagógica, esses termos possuem significados radicalmente diversos; e o fato de solicitarem atitudes do cotidiano escolar incoerentes com as condições de trabalho vigente.

O que depreendo dessa contradição entre a semântica - que faz supor uma maior liberdade das escolas no processo de construção de seus currículos, os quais deveriam emergir das vivências cotidianas - e o explicitado no documento é que a legislação, ao mesmo tempo em que enfatiza a liberdade, sente-se na obrigação de prescrever minuciosamente o traçado do caminho.

Nossos legisladores se assemelham ao papel da Igreja Católica explicitado por Ivã, personagem de Dostoiévski, no livro "Os Irmãos Karamazov". Para impedir que os cristãos, no exercício da liberdade, se tornassem infelizes e pecadores, a Igreja preferiu assumir o ônus da culpa, passando a estabelecer normas rígidas de conduta e retirandolhes a possibilidade do livre arbítrio, sob o argumento de que "não há nada de mais sedutor para o homem do que o livre arbítrio, mas também nada de mais doloroso". (DOSTOIÉVSKI, 1971, p.190).

O grande problema das reformas educacionais é que elas incidem em aspectos pedagógicos e administrativos sem levar em consideração a realidade, ou seja, o dia-a-dia das escolas. São urdidas em gabinetes, pensadas para cenários idealizados, elaboradas de forma complexa. Utilizam conceitos de ponta nas pesquisas e na literatura educacional, descuidando do fato de que no outro extremo, onde as propostas devem ser efetivadas, há professores com formação precária e cursos de formação de professores que levam muito tempo para apropriar-se de novas posturas, quando não as criticam com acidez e as rejeitam de imediato.

Nas escolas há medo, insegurança, rejeição, insatisfação, indignação, falta de aporte teórico e de cursos de capacitação, condições inadequadas de trabalho, ausência de material para consulta, carência de espaço e tempo para discussões, entre vários outros aspectos que dificultam a superação do instituído e a incorporação do instituinte.

Difícil situação esta da escola: a de viver no fio da navalha, ansiando por definições que demoram a acontecer; atendendo a solicitações sem contar com os elementos necessários para dar as 
Os parâmetros curriculares nacionais no contexto da reforma educacional brasileira

respostas esperadas e satisfatórias. Enfim, sempre esperando, como diz o poeta, "o trem que nunca vem".

\section{REFERÊNCIAS}

BELLINI, L. M. Lei e cultura: conflitos para e na aprendizagem das crianças. Olho Mágico, Londrina-PR, p. 5-6, 2001.

BRASIL. Conselho Nacional de Educação. Parecer CEB n. 15/98. Aprovado em 01/06/98. Disponível em <http://www.Inep.gov.br>. Acesso em: 25 mar. 2001.

BRASIL. Conselho Nacional de Educação. Resolução CEB n.1, de 7 de abril de 1999. Disponível em <http:// www.inep.gov.br>. Acesso em: 25 mar. 2001.

BRASIL. Ministério da Educação, Secretaria da Educação Média e Tecnológica. Parâmetros Curriculares Nacionais do Ensino Médio. Brasília, DF: Ministério da Educação, 1999.

BRASIL. Ministério da Educação, Secretaria da Educação. Lei 9.131, de 24 de novembro de 1995. Disponível em <http:// www.inep.gov.br>. Acesso em: 25 mar. 2001.

BRASIL. Lei 5692/71, de 11 de agosto de 1971. In: SAVIANI, Dermeval. Política e educação no Brasil: o papel do Congresso Nacional na Legislação do Ensino. São Paulo: Cortez: Autores Associados, 1987. p.133-144.

BRASIL. Ministério da Educação e do Desporto, Secretaria de Educação Superior. Edital n. 4/97.

BRASIL. Secretaria de Educação Fundamental. Parâmetros Curriculares Nacionais: introdução aos parâmetros curriculares nacionais. Brasília, DF: MEC/SEF, 1997.

BRASIL. Lei n. 9.394, de 20.12.96: estabelece as Diretrizes e Bases da Educação Nacional. São Paulo: Saraiva, 1997.

BRASIL. Conselho Nacional de Educação. Parecer CEB n. 3/97. Disponível em <http:// www. Inep.gov.br>. Acesso em: 25 mar. 2001.

BRASIL. Conselho Nacional de Educação. Resolução CEB n. 2, de 7 de abril de 1998. Disponível em <http:// www. Inep.gov.br>. Acesso em: 25 mar. 2001.

BRASIL. Conselho Nacional de Educação. Resolução CEB n. 3, de 26 de junho de 1988: institui as Diretrizes Curriculares para o Ensino Médio. Brasília, DF: Ministério da Educação, 1999. 
BRASIL. Ministério da Educação e do Desporto. Secretaria de Educação Fundamental. Referencial Curricular Nacional para a Educação Infantil. Brasília, DF: MEC/SEF, 1998.

BRASIL. Ministério da Educação e do Desporto. Secretaria de Educação Fundamental. Parâmetros Curriculares Nacionais: terceiro e quarto ciclos do ensino fundamental. Brasília, DF: MEC/SEF, 1998.

BRASIL. Secretaria de Educação Fundamental. Parâmetros Curriculares Nacionais: língua portuguesa. Brasília, DF: MEC/SEF, 1997.

BRASIL. Secretaria de Educação Fundamental. Programa de Desenvolvimento Profissional Continuado: educação infantil. Brasília, DF: A Secretaria, 1999 (Parâmetros em Ação).

DOSTOIÉVSKI, F. M. Os irmãos Karamazov. São Paulo: Abril, 1971. [Coleção Os Imortais da Literatura Universal].

FERNANDES, A. V. M. Entre o texto e o contexto: diretrizes para a reorganização do ensino médio da rede estadual de ensino. Revista da Educação. São Paulo, APEOESP, n.10, p.45-47, maio, 1999.

GOODSON, I. F. Currículo: teoria e história. 2.ed. Petrópolis, RJ: Vozes, 1995.

HERNÁNDEZ, F. Transgressão e mudança em educação: os projetos de trabalho. Porto Alegre: ArtMed, 1998.

MORAES, M. C. O paradigma educacional emergente. Campinas: Papirus, 1997.

MOREIRA, A. F. B. A psicologia e o resto: o currículo segundo César Coll. Cadernos de Pesquisa, São Paulo: Fundação Carlos Chagas, n.100, p.93107, mar. 1997.

PARANÁ. Secretaria de Estado da Educação. Coordenação de Informações Educacionais. Dez Anos de Educação no Paraná. Curitiba, 2001.

RIOS, T. A. Ética e competência. 10. ed. São Paulo: Cortez, 2001. [Coleção Questões da Nossa Época, v.16].

SILVA JÚNIOR, C. A. Parâmetros curriculares nacionais: uma discussão em abstrato. In: SILVA, Carmem Sílvia Bissoli; MACHADO, Lourdes Marcelino. (Orgs.). Nova LDB: trajetória para a cidadania? São Paulo: Arte $\varepsilon$ Ciência, 1998. p.87-92.

SOUZA, P. R. Formação do educador e avaliação educacional: avaliando a política educacional implementada. In: BICUDO, M. A.V.; SILVA JÚNIOR, C. A. (Orgs.). Formação do educador e avaliação educacional. São Paulo: UNESP, v.3, 1999. p.19-30. 
Os parâmetros curriculares nacionais no contexto da reforma educacional brasileira

VALENTE, S. M. P. Parâmetros curriculares nacionais e avaliação nas perspectivas do Estado e da escola. Marília, 2002. Tese (Doutorado em Educação) - Universidade Estadual Paulista, Marília, 2002.

UFRGS/FE. Análise do documento "Parâmetros Curriculares Nacionais". In: SILVA, L. H.; AZEVEDO, J. C.; SANTOS, E. S. Reestruturação curricular: novos mapas culturais, novas perspectivas educacionais. Porto Alegre: Sulina, 1996, p. 123- 136.

YUS, R. Temas transversais: em busca de uma nova escola. Porto Alegre: ArtMed, 1998.

Enviado em: 03/09

Aceito em: 10/09 